\title{
An iron-regulated outer-membrane protein specific to Bordetella bronchiseptica and homologous to ferric siderophore receptors
}

\author{
Bernard Beall and Theresa Hoenes
}

Author for correspondence: Bernard Beall. Tel: +1 404639 1237. Fax: +1 4046393123.
e-mail: beb0@ciddbd2.em.cdc.gov

Childhood and Respiratory Diseases Branch, National

Center for Infectious

Disease, Centers for

Disease Control and

Prevention, Mailstop C02,

1600 Clifton Road, NE

Atlanta, GA 30333, USA

\begin{abstract}
The bfrA (Bordetella bronchiseptica ferric iron repressed outer-membrane protein) gene was cloned from Bordetella bronchiseptica by screening a library of TnphoA insertion mutants for iron-repressed fusions to phoA. The bfrA gene encoded an $80 \mathrm{kDa}$ outer-membrane protein with a high level of amino acid sequence identity to several bacterial proteins belonging to the family of Ton B-dependent outer-membrane receptors. BfrA was especially homologous to Cir of Escherichia coli, IrgA of Vibrio cholerae and to three previously characterized ferric enterobactin receptors. DNA hybridization results indicated that bfrA was not present in other Bordetella species. Expression of the bfrA gene was induced by low iron availability from a promoter overlapped by a sequence resembling a consensus Fur-binding sequence, and bfrA expression was derepressed in a B. bronchiseptica fur mutant. Utilization of the Bordetella siderophore alcaligin and the exogenous siderophore enterobactin was unaffected in bfrA mutants. Upon attempting to find the specificity of BfrA, 2,3-dihydroxybenzoylserine (DHBS) was shown to be utilized in a bfeA (Bordetella ferric enterobactin receptor gene)-dependent manner by $B$. bronchiseptica and B. pertussis. In addition, the hydroxamate siderophores ferrichrome and desferrioxamine $B$, and the iron source haemin were shown to be utilized independently of bfeA and bfrA in B. bronchiseptica and B. pertussis.
\end{abstract}

Keywords: Bordetella, TonB-dependent receptors, iron sources

\section{INTRODUCTION}

In extracellular bacterial pathogens, uptake of the essential metal iron is often facilitated by the secretion of siderophores capable of binding ferric iron with high affinity. In many Gram-negative species these ferric siderophores are then internalized via specific outermembrane receptors. Bordetella species are known to secrete the hydroxamate siderophore alcaligin to scavenge iron upon iron limiting conditions (Moore et al., 1995; Brickman \& Armstrong, 1996a). Some of the genes involved in alcaligin synthesis have been identified

\footnotetext{
Abbreviations: AP, alkaline phosphatase; DP, 2,2-dipyridyl; DHB, 2,3dihydroxybenzoate; DHBS, 2,3-dihydroxybenzoylserine; EDDHA, ethylenediaminedi(o-hydroxyphenylacetic acid); OMP, outer-membrane protein; SC, Stainer-Sholte minimal medium with Casamino acids; XP, 5-bromo-4chloro-3-indolyl phosphate.
}

The GenBank accession number for the nucleotide sequence reported in this paper is U56084. recently (Giardina et al., 1996; Kang et al., 1996; Brickman \& Armstrong, 1996b).

In addition to utilizing endogenous siderophores, many bacteria are also capable of taking up ferric complexes containing siderophores secreted by other organisms. The important mammalian respiratory pathogens $B$. bronchiseptica, B. pertussis and B. parapertussis contain the $f e p A$ gene homologue, $b f e A$, and the former two species have been shown to utilize the exogenous siderophore enterobactin in a process requiring the receptor BfeA (Beall \& Sanden, 1995b).

Genes studied so far that are involved in siderophore biosynthesis and iron uptake in Bordetella are repressed by iron availability (Beall \& Sanden, 1995b; Giardina et al., 1995; Kang et al., 1996) and this repression is apparently mediated by the iron-binding repressor protein Fur (Beall \& Sanden, 1995a; Brickman \& Armstrong, 1995). To identify additional Bordetella genes encoding iron-regulated exported proteins, 
TnphoA mutagenesis of B. bronchiseptica was used. Here we report the sequence and regulation of a gene specific to this Bordetella species that encodes a protein homologous to the bacterial ferric enterobactin receptors FepA (Lundrigan \& Kadner, 1986), PfeA (Dean \& Poole, 1993) and BfeA (Beall \& Sanden, 1995b), the ferric-DHB (2,3-dihydroxybenzoate) and ferric-DHBS (2,3-dihydroxybenzoylserine) receptor Cir (Nau \& Konisky, 1988) and the Vibrio cholerae virulence protein IrgA (Goldberg et al., 1992). During the course of this study, additional iron sources usable by $B$. bronchiseptica and B. pertussis were found.

\section{METHODS}

Media, growth conditions, and antibiotics. L broth was used for growth of Escherichia coli and B. bronchiseptica, and Stainer-Sholte minimal medium (von Koenig et al., 1988) containing $0 \cdot 1 \%$ Casamino acids (SC) was used for growth of Bordetella strains. L agar containing $100 \mu \mathrm{M}$ 2,2-dipyridyl (DP) and $150 \mu \mathrm{g} 5$-bromo-4-chloro-3-indolyl phosphate (XP) $\mathrm{ml}^{-1}$ (DP-XP agar) was used to screen iron-repressed phoA fusions in $B$. bronchiseptica. The iron-limiting medium for Bordetella strain bioassays was SC agar containing $45 \mu \mathrm{g}$ ethylenediaminedi(o-hydroxyphenylacetic acid) (EDDHA) $\mathrm{ml}^{-1}$ (SC-EDDHA). For iron source utilization assays, SCEDDHA was overlaid with $3 \mathrm{ml}$ soft agar containing $10^{6}$ cells $\mathrm{ml}^{-1}$. Disks containing $10 \mu \mathrm{l}$ of different iron sources were laid upon the surface and growth halo diameters for $B$. bronchiseptica and $B$. pertussis strains were measured after incubation at $35^{\circ} \mathrm{C}$ for $16 \mathrm{~h}$ and $48 \mathrm{~h}$, respectively. SC broth supplemented with either $100 \mu \mathrm{M} \mathrm{DP}$ or $50 \mathrm{mM} \mathrm{FeCl}_{3}$ was used for preparation of RNA from B. bronchiseptica strains. Antibiotics were used at the following concentrations ( $\mu \mathrm{g}$ $\mathrm{ml}^{-1}$ ): kanamycin, 35; ampicillin and nalidixic acid, 100; gentamycin, 10.

Iron sources. Enterobactin and DHBS extracts were prepared as described by Porra et al. (1972) and bioassay stocks were $50 \mu \mathrm{M}$ and $200 \mu \mathrm{M}$, respectively. The source of alcaligin used for this study was SC broth culture supernatant obtained from the B. pertussis fur mutant, B013 $\mathrm{NMn}^{\mathbf{R}} 4$ (Brickman \& Armstrong, 1995) grown in the presence of $50 \mu \mathrm{M}$ putrescine (Brickman \& Armstrong, 1996b). The following were obtained from Sigma and the indicated stock concentrations were used in bioassays: haemin, $125 \mu \mathrm{M}$; ferrichrome (from Ustilago sphaerogena), $50 \mu \mathrm{M}$; desferrioxamine B (deferoxamine mesylate), $50 \mu \mathrm{M}$; DHB, 1-30 mM; salicylic acid, 1-30 mM; sodium citrate, $0 \cdot 1-1 \mathrm{M}$; rhodotorulic acid, $1-3 \mathrm{mM}$.

Alkaline phosphatase (AP) assay. AP activities of $B$. bronchiseptica strains containing translational $b f r A-p h o A$ fusions were measured as described by Brickman \& Beckwith (1975).

Transformation and conjugation. Plasmids were transformed into $E$. coli by standard methods. TnphoA mutagenesis (Manoil \& Beckwith, 1985) was performed as described by Taylor et al. (1989) by introducing the suicide plasmid pRT733 into strain 19385 by conjugation with the donor strain SM10( $\lambda$ pir)(pRT733). Transconjugants were selected on DP$\mathrm{XP}$ agar containing nalidixic acid and kanamycin. Plasmid pSS2141 derivatives (see below) were introduced into $B$. bronchiseptica strains by conjugation with the donor strain SM10 as described by Stibitz (1994).

Plasmids and strains. The strains and plasmids used for this study are described in Table 1. Plasmid pSS2141, derived from
pSS1894 (Merkel \& Stibitz, 1995), was used for construction of plasmid pSBG. Plasmid pSBG contains a $b f r A:: \operatorname{Tn} p h o A$ insertion shown in pS233 (Fig. 1a). Plasmid pSPH1 was derived from pSBG in a chromosome walking step described below and in Results. Plasmids pS233 and pS1394 are pUC19 derivatives containing constructs cloned from the $b f r A:$ : TnphoA mutant strains 19233 and 191394, respectively, and the inserts in these plasmids are depicted in Fig. 1(a). Plasmid pSBFE', which was used for insertional inactivation of the $b f e A$ gene in strains 19233 and 191394, is a pSS2141 derivative which contains a 736 bp structural gene fragment of bfeA (Beall \& Sanden, 1995b).

Cloning the bfrA promoter region and structural gene. Transconjugants containing iron-repressed $\operatorname{Tn} p h o A$ fusions were found by replica streaking blue colonies from DP-XP agar onto DP-XP agar and onto XP agar containing $50 \mu \mathrm{M}$ $\mathrm{FeCl}_{3}$. To clone a $b f r A-p h o A$ translational fusion, chromosomal DNA from the TnphoA insertion mutant 19233, containing an iron-repressed $p h o A$ fusion, was cleaved with SalI and ligated with pUC19. This ligation was used to transform $E$. coli strain $\mathrm{DH} 10 \mathrm{~B}$ to kanamycin resistance, resulting in plasmid pS233. Plasmid pS1394 was obtained by the same procedure with partially SalI-digested chromosomal DNA from the iron-regulated TnphoA fusion strain 191394. The BglII fragment from pS233 was cloned into the BamHI site of the conjugative vector pSS2141, resulting in the integrative plasmid pSBG. Plasmid pSBG was introduced onto the chromosome of strain 19385 by conjugation followed by selection for gentamycin and nalidixic acid resistance. Plasmid pSBG contained an SphI site appropriately located such that the vector origin of replication, the bla gene, and downstream $b f e A$ sequence would be cloned in the following chromosome walking step utilizing SphI digestion. For this step, chromosomal DNA from one transconjugant containing a Campbelltype insertion of pSBG was digested with $S p h \mathbf{I}$, followed by ligating the DNA and transforming $E$. coli strain DH10B to ampicillin resistance, resulting in plasmid pSPH1 (Fig. 1).

DNA sequencing. Plasmids pS233, pS1394, pSPH1 and appropriate plasmid subclones were sequenced with Dye-Deoxy Terminator Kits (Applied Biosystems) as described by the manufacturer using oligonucleotides annealing to $b f r A$ region DNA or the M13 multiple cloning site. Reactions were loaded onto $6 \%$ polyacrylamide gels and electrophoresed on an Applied Biosystems 373 Sequencer.

Southern analysis. Southern analysis was performed using Bordetella chromosomal DNA prepared as described previously (Beall \& Sanden, 1995a) with the Genius Kit (Boehringer Mannheim). A 498 bp Sall bfrA structural gene fragment was labelled and used as a probe with hybridization and high stringency washes at $65^{\circ} \mathrm{C}$ as described by the manufacturer. Low stringency Southern analysis was performed by the same protocol, except that hybridization and washes were at $53^{\circ} \mathrm{C}$.

Total- and outer-membrane preparations. Extracts enriched in either total membrane or outer membrane were prepared by sonication followed by high speed centrifugation and Sarcosyl extraction as described by Nikaido (1994).

Immunoblotting. Proteins electrophoresed on 10\% SDSpolyacrylamide gels were transferred and immunostained as described by Blake et al. (1984) with antiserum against purified E. coli AP obtained from 5 Prime-3 Prime Inc.

RNA isolation and primer extension. Total RNA was prepared with kits (5 Prime-3 Prime Inc.) as described by the manufacturer followed by phenol/chloroform extraction and ethanol precipitation. The primer 5' GGCGTCTGGATGCG- 
Table 1. Bacterial strains and plasmids

\begin{tabular}{|c|c|c|}
\hline Strain or plasmid & Genotype or characteristics* & Source or reference \\
\hline \multicolumn{3}{|l|}{ E. coli } \\
\hline SM10 & RP4-2 Tc::Mu conjugation strain & Simon et al. (1983) \\
\hline SM10(גpir) & As SM10, but $\lambda$ pir6K & Taylor et al. (1989) \\
\hline DH10B & $m c r A \Delta m c r B C \Delta h s d R \Delta b s d M d e o R$ recA1 endA1 lacZ $\Delta \mathrm{M} 15$ & BRL \\
\hline \multicolumn{3}{|l|}{ B. bronchiseptica } \\
\hline 19385 & ATCC $19385 \mathrm{Nal}^{\mathrm{R}}$ (wild-type dog isolate) & Laboratory collection \\
\hline 19233 & $\begin{array}{l}\text { 19385(bfrA:: TnphoA), TnphoA insertion at base } 233 \text { of } \\
\text { bfrA }\end{array}$ & This study \\
\hline 191394 & $\begin{array}{l}\text { 19385(bfrA:: TnphoA), TnphoA insertion at base } 1394 \text { of } \\
b f r A\end{array}$ & This study \\
\hline 19233B & $19233 \Omega \mathrm{pSBFE}^{\prime}$ (bfeA insertional mutant) & This study \\
\hline B013N & Wild-type pig isolate & Brickman \& Armstrong (1995) \\
\hline $\mathrm{B} 013 \mathrm{NMn}^{\mathrm{R}} 4$ & $\mathrm{~B} 013 \mathrm{~N}(f u r)$ & Brickman \& Armstrong (1995) \\
\hline B013NW & $\mathrm{B} 013 \mathrm{~N} \Omega \mathrm{pSBG}$ & This study \\
\hline B013NF & $\mathrm{B} 013 \mathrm{NMn}^{\mathrm{R}} 4 \Omega \mathrm{pSBG}$ & This study \\
\hline \multicolumn{3}{|l|}{ B. pertussis } \\
\hline 82 & Wild-type clinical isolate & Beall \& Sanden (1995b) \\
\hline 84 & $82 \Omega \mathrm{pKS} 3$ (bfeA insertional mutant) & Beall \& Sanden (1995b) \\
\hline \multicolumn{3}{|l|}{ B. parapertussis } \\
\hline A168 & Wild-type clinical isolate & Beall \& Sanden (1995b) \\
\hline \multicolumn{3}{|l|}{ Plasmids } \\
\hline pSS2141 & Broad host-range integrational vector, $\mathrm{Gm}^{\mathrm{R}} \mathrm{Ap}^{\mathrm{R}}$ & Merkel \& Stibitz (1995) \\
\hline $\mathrm{pSBFE}^{\prime}$ & $\begin{array}{l}\text { pSS2141 containing a } 736 \text { bp structural gene fragment of } \\
\text { bfeA, for integrational inactivation of } b f e A\end{array}$ & This study \\
\hline pS233 & $\begin{array}{l}\text { pUC19 containing a Sall fragment, encompassing } 77 \text { codons } \\
\text { of } b f r A \text { fused to } p h o A \text { and the } \mathrm{Km}^{\mathrm{R}} \text { gene cloned from } \\
\text { TnphoA mutant strain } 19233\end{array}$ & This study \\
\hline pSBG & $\begin{array}{l}\text { pSS2141 containing a BglII fragment from pS233, } \\
\text { encompassing the } b f r A-p h o A \text { fusion }\end{array}$ & This study \\
\hline pSPH1 & $\begin{array}{l}\text { Contains entire } b f r A \text { gene and flanking sequence, obtained } \\
\text { by homologous integration of pSBG followed by excision } \\
\text { with } S p h \mathrm{I} \text {, ligation and transformation of } E \text {. coli to } A \mathrm{p}^{\mathrm{R}}\end{array}$ & This study \\
\hline pS1394 & $\begin{array}{l}\text { pUC19 containing a SalI fragment, encompassing } 464 \text { codons } \\
\text { of } b f r A \text { fused to } p h o A \text { and the } \mathrm{Km}^{\mathrm{R}} \text { gene cloned from } \\
\text { Tn } p h o A \text { mutant strain } 191394\end{array}$ & This study \\
\hline
\end{tabular}

" $\Omega$ indicates the strain contains a single homologous inserted copy of the indicated plasmid. Ap ${ }^{\mathbf{R}}$, ampicillin resistance; $\mathrm{Gm}^{\mathrm{R}}$, gentamycin resistance; $\mathrm{Km}^{\mathrm{R}}$, kanamycin resistance; $\mathrm{Nal}^{\mathrm{R}}$, nalidixic acid resistance.

TGCGTGGAATG $3^{\prime}$, complementary to bases $524-548$ of the $b f r A$ sequence represented in Fig. 2 was end-labelled with ${ }^{32} \mathrm{P}$ using T4 polynucleotide kinase. Approximately $1 \mathrm{pmol}$ of primer was annealed to $40 \mu \mathrm{g}$ total RNA at $60^{\circ} \mathrm{C}$ and extended at $52^{\circ} \mathrm{C}$ with avian myeloblastosis virus reverse transcriptase (Promega) as described by Moran (1993).

\section{RESULTS}

\section{Cloning and nucleotide sequence of the bfrA gene}

Following TnphoA mutagenesis of $B$. bronchiseptica strain 19385, iron-repressed translational fusions to $p h o A$ were identified by screening kanamycin-resistant blue colonies on DP-XP plates for those requiring DP for full expression of AP. Of a total of approximately 3000 initial blue colonies, 12 independent colonies meeting this criterion were picked for further analysis. Three of these were found later by sequence and Southern analysis (data not shown for one of these) to contain independent insertions within the same gene, bfrA, which is the focus of this study. Studies with the remaining nine TnphoA mutants are in progress. The putative $b f_{r} A$ iron-repressed promoter and chromosomal DNA downstream of the $b f r A$ promoter were cloned using the strategy described in Methods. This involved digesting chromosomal DNA from the TnphoA insertion strain 19233 with SalI, which cleaved within $\operatorname{Tn} p h o A$ adjacent to the $p h o A$ and kanamycin resistance gene sequences (Fig. 1a). Ligation of this digest with plasmid pUC19 followed by transforming strain DH10B to kanamycin resistance resulted in the isolation of plasmid pS233 (Fig. 1a), which was found to 
(a)
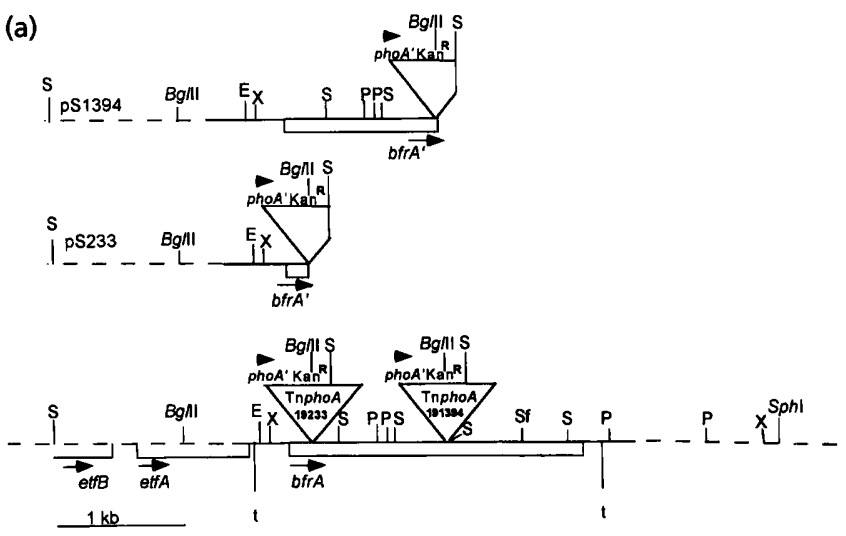

(b)

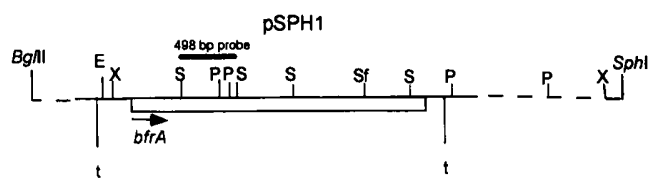

Fig. 1. (a) The B. bronchiseptica bfrA chromosomal region, TnphoA fusions isolated during this study and relevant plasmid inserts. The bfrA region is shown with the positions of two independently isolated TnphoA insertions (bases 233 and 1394 of the bfrA structural gene within strains 19233 and 191394, respectively). The solid line indicates sequenced DNA shown in Fig. 2. $t$ designates sequences that may function as transcriptional terminators. Plasmids pS233 and pS1394 are pUC19 derivatives containing the indicated bfrA-phoA fusions. These plasmids were obtained by digestion of chromosomal DNA of the respective TnphoA mutants with Sall, ligation and transformation of $E$. coli to kanamycin resistance. Just upstream of bfrA lie homologues of electron transfer flavoprotein subunit genes etfA and etfB located by partial sequence analysis. E, EcoRl; P, Pstl; S, Sall; Sf, Sful; X, Xmnl. (b) Diagram of insert in plasmid pSPH1 containing the entire bfrA gene. This plasmid was obtained in a chromosome walking step. A conjugative plasmid, pSBG (a derivative of pSS2141) containing the Bg/ll fragment from pS233 was integrated into the B. bronchiseptica chromosome by selecting for gentamycin resistance, followed by digestion of the chromosomal DNA with $S p h l$. Sphl cleaved downstream of bfrA (shown), and also in an appropriate location within the integrated pSS2141 vector sequence (not shown). The ligated Sphl-digested chromosomal DNA was used to transform $E$. coli to ampicillin resistance, resulting in pSPH1. The 498 bp bfrA structural gene fragment used as a probe for Southern analysis in Fig. 6 is indicated.

contain the $5^{\prime}$ end of a gene later designated $b f r A$. Next, a BglII fragment from pS233, consisting of a $1.2 \mathrm{~kb}$ fragment of $B$. bronchiseptica DNA fused to a $3.4 \mathrm{~kb}$ portion of TnphoA, was subcloned into the BamHI site of the conjugative integrable vector pSS2141. The resulting plasmid, pSBG, was used in a chromosome walking step that resulted in plasmid pSPH1. Plasmid pSPH1 contained an additional $3.4 \mathrm{~kb}$ of DNA downstream of the initial phoA fusion in strain 19233 (Fig. 1b).

The DNA sequence of $\mathrm{pS} 233$ revealed an ORF extending 77 codons to the junction of the phoA fusion in strain 19233 (Fig. 1a; Fig. 2, position 712). The DNA sequence of $\mathrm{pS} 1394$, containing a chromosomal fragment from bfrA::TnphoA mutant strain 191394, overlapped and extended this ORF, designated $b f r A, 464$ codons to the junction of this $p h o A$ fusion (Fig. 1; Fig. 2, position 1775). Finally, plasmid pSPH1 was found to include the entire $b f r A$ structural gene consisting of 734 codons (Fig. 1 b; Fig. 2, positions 482-2743). Just downstream of the bfr $A$ stop codon lies an inverted repeat which possibly functions as a transcriptional terminator (Fig. 2, positions 2770-2802).

A search of the SWISS-PROT protein database revealed significant homology of the deduced $b f r A$ product with several proteins in the family of TonB-dependent receptors (not shown). BfrA had the most amino acid sequence identity with $\operatorname{Cir}(34 \%), \operatorname{IrgA}(33 \%)$, BfeA $(26 \%)$, PfeA $(25 \%)$ and FepA (22\%) (Fig. 3). Regions of the BfrA protein with the most pronounced homology to these outer-membrane proteins (OMPs) included a "Ton B box' (region I in Fig. 3) and two other portions highly similar to sequences conserved in Ton B-dependent receptors (regions II and III, Fig. 3). There are two regions of FepA implicated in other studies as putative ligand-binding sites (Murphy et al., 1990) (bold sequences in Fig. 3). While well conserved between the ferric enterobactin receptors FepA, PfeA and BfeA, these regions are not well conserved or absent in BfrA, IrgA and Cir.

A signal peptide of 43 residues was predicted for $\mathrm{BfrA}$ (von Heijne, 1985), similar to the predicted PupA (Pseudomonas putida ferric pseudobactin receptor) leader peptide in that it is unusually long and has an extended basic $\mathrm{N}$-terminal region containing 6 basic residues (Fig. 3; Bitter et al., 1991). Among the features conserved between BfrA and many other OMPs are a Cterminal phenylalanine and an arginine residue at position -11 relative to the $\mathrm{C}$ terminus (Fig. 3).

Although not the focus of this study, other features of the sequence shown in Fig. 2 include the $3^{\prime}$ end of an apparent homologue of etfA (Finocchiaro et al., 1988; Bedzyk et al., 1993) which together with et $f B$, encode the $\alpha$ and $\beta$ subunits of electron transport flavoproteins (Fig. 2 ). Upstream of etfA lies etfB ( $\beta$ subunit flavoprotein gene), which was found by partial sequence of the region upstream of $\operatorname{etfA}$ (Fig. 1a, data not shown). Downstream of $\operatorname{etf} A$, and just upstream of a possible transcriptional terminator, lie eight perfect repeats of the 9-base sequence GCACCCCAC. The significance of this unusual repeated sequence is unknown.

\section{Expression of the bfrA gene}

In the presence of DP, both of the $B$. bronchiseptica bfrA::TnphoA mutant strains 19233 and 191394 showed iron-repressed AP activity (Table 2). To determine if $b f r A$ gene expression was Fur-regulated, plasmid pSBG, which contains a $b f r A-p h o A$ translational fusion, was introduced as a Campbell-type insertion into the fur mutant B013NMn ${ }^{\mathrm{R}} 4$ (Brickman $\&$ Armstrong, 1995) and its wild-type parental strain B013N. Activity of this fusion was constitutive in the fur mutant strain in iron-replete and iron-limiting con- 
CGTGGCCATCAACAAGGATCCGGAAGCGCCGATGTTCGGCGTCGCCGACTACGGCCTGGTGGGCGACCTGTTCCAGGTCGTGCCCGAACTGACCGGCGCGCTCTGAGCGGCGCCTGTCCC 120

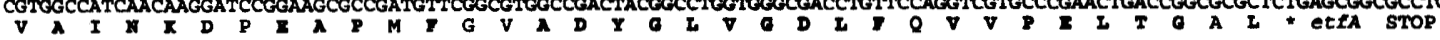

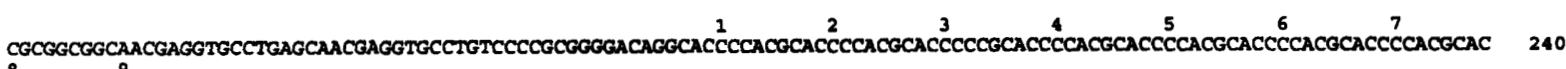

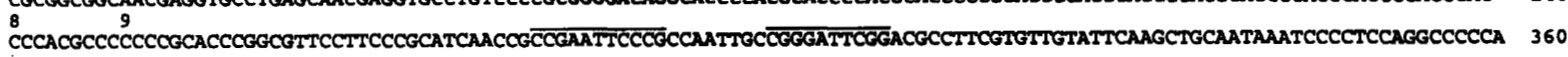

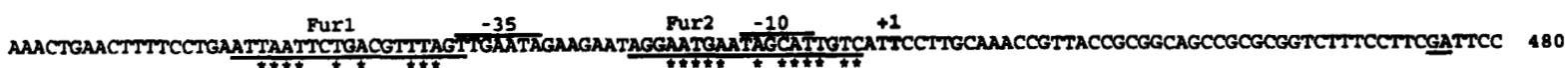

bfrA start

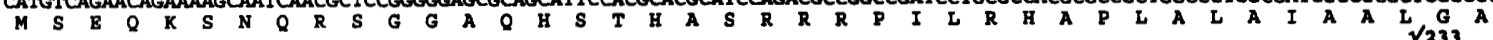
CGCCCAGGCCCAGACCGCCAGCCCGCAGGAGACACCCTGGGCATCACGCAGATGGACACCGTGGTCGTGACCGCCTCCGGGTTCGAGCAGGAAATCAAGAACGCGCCGGCCTCGATCTC 720

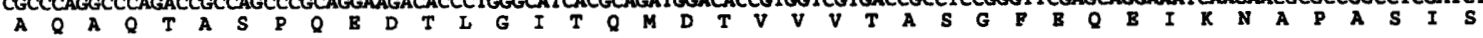
CGTCATCACCCGCGAGCAGCTCGAAAGCAAGCCCTTCCACAACCTGGCCGACGCGGTCGCCGACGTCGAAGGCGTCAGCGTCGAACGCGGCGGCAAGGCGGGCGGCATGAACATCAGCAT 840

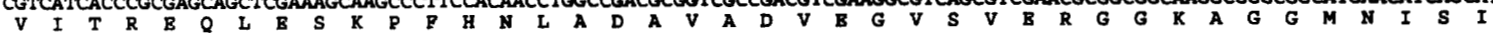
CCGCGGCCTGCCCAGCGACTACACCCTGGTGCTGGTCGACGGCAAGCGCCTGAGCCAGAACAGCTCGGGCGCCCGCCCCAACGGCTTCGGCGACGTGGACACCAACTTCATCCCGCCCAT 960 R G L GTCCGCCATCGACCGCATCGAAGTCGTGCGCGGCCCTATGTCCACCCTGTATGGCTCGGACGCCATGGGCGGCGTGATCAACATCATCACCCGCAAGGTCGCCAGGGATGGACCGGCCA 1080

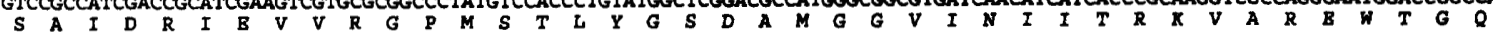
GGTCACGCTGGACGGCACCGCCCAGGGCGACAACCGCTACGGCAACAACTACGGCTCGTCGTTCTACCTGAGCGGCCCGCTGCAGACCGACAAGCTGGGCCTGTCGCTECGCGGAGGCCT 1200 V T L D G T A O G D N R Y G N N Y G S S F Y L S G P L GTACCGTCGCCTGAGCGCGCACGGCAGCTACCCGGCCAACCAGGCCGAATACGACAGCGGCGACTACTCCGGCGACATCGCCAGCTTCAGCGGCCTGGGCGACAGCCTGCAGCGCAACGT 1320

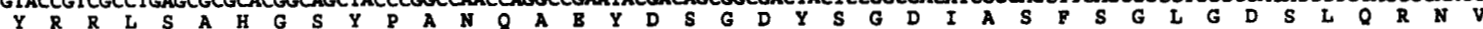
CGGCCTGCGCCTGGCGCTCACGCCCAACCGCAACCACGACATCCTGTTCGACGTCGACGCCAACTGGCAGACCTTCGACAACGCCAACGGCGAACTCGGCACCCTCAACGCCGACGTGGC 1440

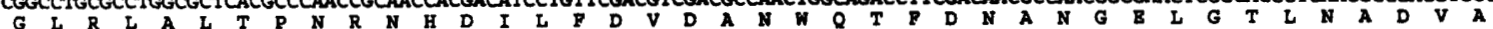
GCCCAACCGCCAGGGCGGCGGCTATGAGCCCGAGATGAAGTTCAATCGCCAGCGCTACGCCCTGACCCACCTGGGCCGCTACGACGGCGCGATCAGCTCCGACACCAGCCTGCTGTACGA 1560

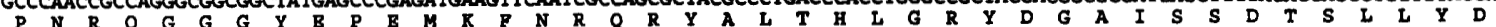
CACCACCGAGACCATCGGCCGCACCAACCCCATGAGCACGCCGCGCCAGCCGAGCGATGGGGAAAGCGCGAACTGGAATACGAGAACTGGGTGTTCGACACCAAGTGGACCATGCCCCT 1680

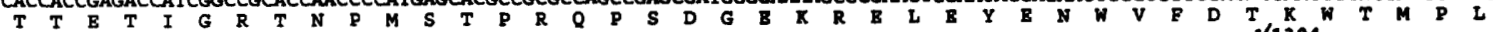

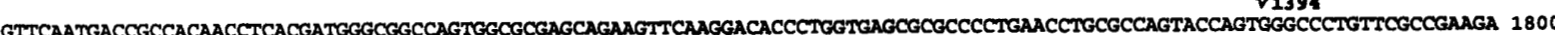
P N CGAATGGCGCATCGTCGACGACCTGGCCCTGACCATGGGCGCGCGCTATGACCGCAACGAGCAGTTCGGCGGCAAGTGGAGCCCGCGCGGCTACCTGGTCTGGAACGCCACGCCGGCCTG 1920 $\underset{B}{\text { W }}$ R I V D D I A L T M G A R GACCGTCAAGGGCGGCGTCAGCAAGGGCTACAAGACGCCGGACATCAACCTCATGACCGACGGCATCATCGGCCTGGGCGCGCAAGGCACCATGCCGCTGCTGGGCAACTCGCAGCTCAA 2040

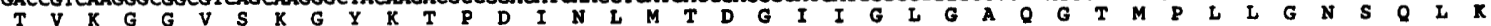
GCCGGAATCCAGCACCTCGTCCGAACTCGGCGTGCTGTTCGACGACGGCGAAGGACTGACGGGCAACCTGACCGGCTTTCACACCAAGTTCAAGGACAAGATCGACACCCAGAACGTGCC 2160

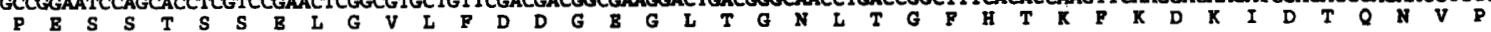
CAACTGCCTGGCCGCCGGCGGCCCCGTGCCGGGGTGCCTGGACCTGGGCGTGTGGGAGCGCAACGGCGTGCCEGTGGCCAACTTCTCGCAACGCGTGAACGTGGATACCGCCACCATCCA 2280

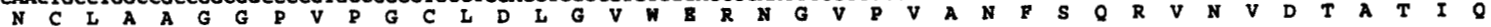
GGGCTTCGAGCTGGGCGGCGCATCCCGCTGTTCGAAGGCTGGTCCTTCAGCGGCAACTACACCCTTACCGCCAGCGAAATCACCTCCGGCGCCAAGCAGGGCCAGCCGCTGGGCTCGCA 2400

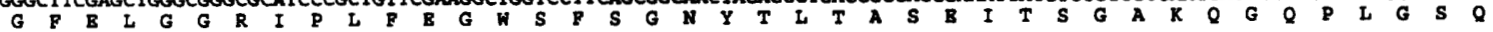
GCCGCGCCACAGCCTGAACCTGGGCCTGAACTGGCGCGTCAACGAACGCTTCAACGCCTGGGTGCGCGGCGAGTACCGGGCCAAGCAGTTCAACGACATGAACTGGGAAAGGAGCAGGT 2520

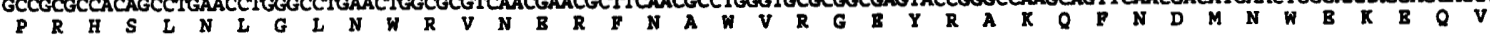
GTTCTACAGCCCGTACTGGCTGGCCAGCCTGGGCGGCTCGTACGTGCTGAACAAGAACGTGACGCTGTCEGCCTCGGTGTACAACCTGTTCGACAAGAACTTCGTCGACTACGGCCCCAC 2640

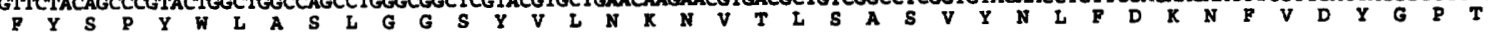
CAAGGTCGGCACCAGCGCCCCCACGGCCGCCACCTCGTGGAGCAACTCGTACCGCCAGGTGCTGGAAGGCCGCCGCCTGTGGGTGTCGGCGAACATTACGTTCTGATCCCGCGAAAGCG 2760

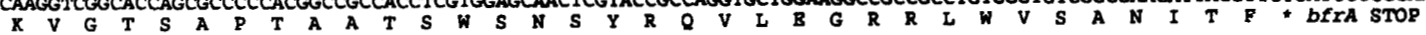
GCAACCGCAAAGGAAAGCCGGCGAAGCCGGCTTTTCCTTGTCGGCGCCGGCGCGCCCTACTGCGGTTGCAGGCCGGCGTCCTTGACGATEGCGCCCCAGCGCGGCAGCTCCTCACGCA 2880 GCATGGCCTCGAACCCTTGCGGCGTGGTCGTATGCGCCACCACCCCGGAGGTTCTCCAGCTTCTCEGTCACTTCCTTTTCCTGCAGCACGGCGTTGAACACGCTGTTCAGCTTCTCCACC 300O ACCGCGGGCTGCGCGCCCTIGGGCAGCAGGAAGCCGATCCAGACGTGCGCCGGGACGGTGCCAAAGCCGCTITCCTTCATGGTGGGCACGTCCGGGAACAGCTTGAGGCGGTCCTCGGAG 3120 CCGATGGCCAGCGCCTTCAGCTTGCCCGACTGACGAACGCCTGCACGG 3169

Fig. 2. Nucleotide sequence of the bfrA gene and the amino acid sequence of the ORF BfrA. Inverted repeats possibly functioning in transcription termination are overlined (positions 284-313 and 2770-2802). A minimal potential ribosome binding site is indicated at positions 474-475 (underlined). -35 and -10 hexamers homologous to corresponding regions of $\sigma^{70}$-recognized promoters are overlined upstream of the transcriptional start site $(+1)$, a $T$ residue at position 432 (in bold type). Two 19-base sequences with homology to the consensus iron box recognized by the $E$. coli Fur protein are underlined with asterisks below bases conserved with the consensus. The positions of the TnphoA insertions in strains 19233 and 191394 are indicated by $\sqrt{ } 233$ and $\sqrt{ } 1394$, respectively. Upstream of the potential terminator preceding $b f r A$ are eight perfect repeats of the sequence GCACCCCAC, which is situated downstream of an etfA (electron transport flavoprotein subunit $\alpha$ ) homologue.

ditions, while the parental strain showed iron-repressed AP activity (Table 2 ).

Primer extension of total RNA from iron-starved wildtype $B$. bronchiseptica with an end-labelled primer revealed a transcript with a $5^{\prime}$ terminus mapping to position 432 (Fig. 2; Fig. 4, lane 1). This $5^{\prime}$ transcript terminus maps just downstream of a sequence (TTGAAT-17 bp-TAGCAT) with high similarity to the consensus sequence of $E$. coli $\sigma^{70}$-directed promoters (TTGaca-17 bp-TAtaAT; the upper case positions are the most conserved) (Hawley \& McClure, 1983). Overlapping the -10 hexamer just upstream of the transcript $5^{\prime}$ terminus lies a sequence identical in 12 of 19 positions 


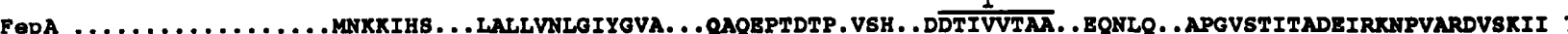

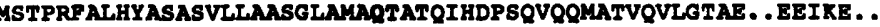

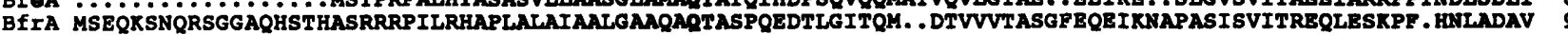

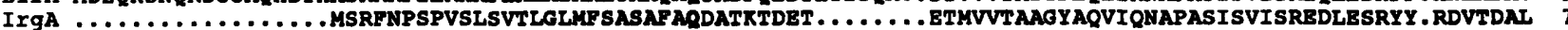

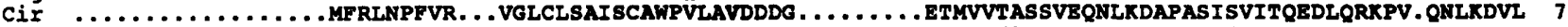

II

FOPA RTMPGVNLTGNSTSGORGNNRQIDIRGMGPENTLIIIDGKPVSSRNSVROGWRGERDTRGDTSWVPP.EMIERIEVLRGPARARYGIGATGGWVIITTK PFEA RTMPGVNLTGNSSSGRGNIRQIDIRGMGPENTLILVDGKPVSSRNSVRYGWRGERDSRGDTWWVPA. DQVERIEVIRGPAAARYGNGNAGGVVNI ITKO BfEA RREPGVNLTGNSASGARGNSRQVDIRGMGPENTLILIDGKPVTSRNAVRYGWNGDRDTRGDTWWVPA.EEVERIEVIRGPAAARYGSGAMGGVVNI ITKR BfIA ADVEGVSVER . . . . GGKAGGVNISIRGLPSDYTLVLVDGKRLSONSSG . . ARPNGEG.DVDTNFIPPMSAIDRIEVVRGPMSTLYGSDAYGGVINI ITRK

I KGA KSVPGVTVTG . . GG . DTTDISIRGMGSYYTIIIVDGKR. . OTSRO. . TRPYSDGPGIEOGWLPLOAIERIEVIRGPHSTLYGSDAIGGVIKIITRK

IrgA KSVGVGT ....

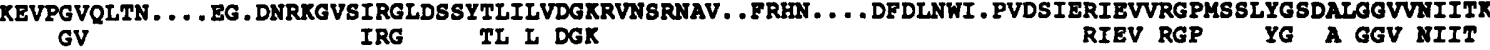

FePA GSGBWHGSWDAYFNAPEHKEEGATKRTNF SLTGPL.GDEFSFRLYGNLDKTQADAWDINQGHQSARAGTYATTLP. . AGREGVINKDINGVVRWDFAPLO PFOA AGAETHGNLSVYSNF PQHRAEGASERYSFGLNGPL. TENLSYRVYGNIAXTDSDDWDINAGHESNRTGKQAGTLP. . AGREGVRNKDIDGLLSWRLTPEQ BfEA PADRATGSITYYTNOPEDSREGNTNRVMARISAPI. SDTLSMRL YGNYMKTWPDARDINAGHANTSDNGNPST . . . AGREGVINQDLSALESWKADSEN BF VA VAREWTGOVTLDGTAOGDNRYGNYGSSFYLSGPLOTDKLGLSLRGGLYRRLSAHGSYPANOAEYDSGDY SGDIASF SGLGDSLORNVGLRLALTPNRNH I IGA DQQQWSGNVQLSTVVQENRASGDEQSANFFVTGPL. SDALSLQVYGQTRQR. . . . . . DEDEIE........... HGYGDKSIRSLTSKLNYQLNPDH Cir IGQKWSGTVTVDTTIQEKRDRGDTYNGQF FTSGPLIDGVLGWKAYGSLARR. . . . . EKDDPQNSTTTDTGETPRIEGFSS ...RDGNVEFAWTPIQNH $\mathbf{G}$ G $\mathbf{P}$ G

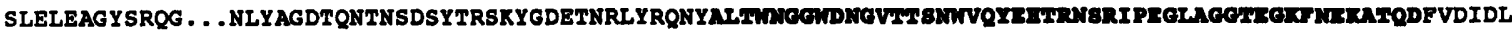
TLEFEAGF SRQG . . . NI YTGDTONTNSWNYVROMLGHETWRMYRETYSVTHRGEWDFGSSLA. YLQYEKTRNSRINEGLAGGTEGIFDPNNA. GFYTATL TVDLDMGFSROG . . NTFAGDTMNANSDFSDSLYGKETNAMYRENYALTHRGVYDWGTSRAS VGYDYTRNAROREGLAGGPEG . . APTAGGYDTARI

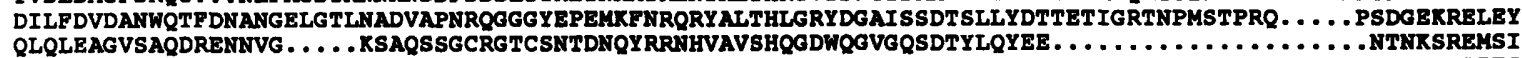
DFTAGYGFDRQDRDSD. . . . . . . . . . . SLDKNRLERQNYSVSHIGRWDYGTSELKYY........... $\mathbf{Q}$

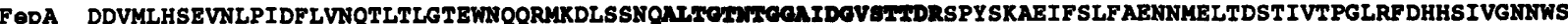

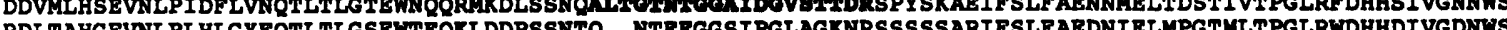
KNWRAAAEASVPFHLGFEOVATVGVEWLRESLEDPAGTRQ . . TYTGGAIGGTAPADRDPKSRQTSYALF AEDNIEIDERTYLTPGVRLDHNSEFGSNNS

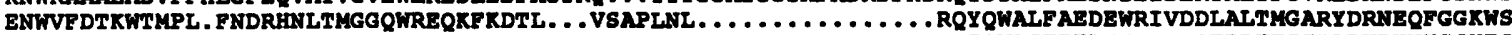

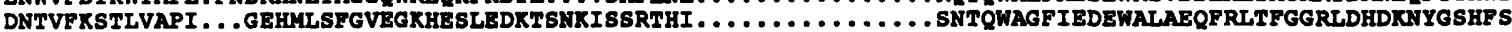
ESNTVDGKYTLPL. TAINQFLTVGGEWRHDKLSDAVNLTGGTSSKT . . . . . . . SASQYALFVEDEWRIFEPLALTTGVRUDDHETYGEKWS

PALNISQGLGDDFTLKMGIARAYKAPSLYQTNPNY ILYSKGQGCYASAC . . . GCYLQGNDDLKAETSINKEIGLEFKRD. . . . GWLAGVTHFRWDYRNK PSLNLSHALTERVTLKAGIARAYKAPNLYQLNPDYLLY SRGQGCYGQST . . SCYLRGNDGLRAETSVIKELGIEY SHD. . . . GLVAGLTYFRNDYKUK PSLNASYAVTD. . ALKGGIARAY KAPNLYQSNPNYLIY SRGNGCLASQTWTWGCYLVGNEDLSPETSVNKEIGFEYDPG . . . . TWRTSYAYFRADYRNK PRGYLVWNATPAWTVKGGVSKGYKTPDINEMTDGI. . . . . . . IGLGAOGTUPLLGNSOLKPESSTSSELGVLFDDG . . . EGLTGNLTGEHTKFKDK PRVYGVWNLDPLWTVKGGVSTGFRAPQLREVTPDW. . . . . . . . GQVSGGGN . . IYGNPDLOPETSINKELSLMYSTG. . . SGLAASLTAFHNDFRDK PRAYLVYNATDTVTVKGGWATAPKAPSLLQLSPDW. . . . . . . TSNSCRGACKIVGSPDLKPETSESWELGLYYMGEEGWLEGVESSVTVPRNDVRDR

$$
\mathbf{K} \text { G P }
$$$$
\text { G I E S E }
$$

FepA

IEAGYVAVGQNAVG . . . . . . . . . TD. . . . . LYQWDAVPKAVVEGLEGSLNVPVSETVMWTNNITYML. .KSENKTTGDRLSIIPEYTLNSTLSWQ IESGLSPVDHASGG . . . . . . . . . . RGDYANAAIYOWENVPXAVVEGLEGTLTLPLADGLXWSNNLTYML . . QSKNKETGDVLSVTPRYTLNSMLDWO IVAGTDVOYRLANG . . . . . . . . . . . ARVLOWTNSGKAVVEGLEGNLEI PLASWLDWNTNPTYMI . OSKEKATGEPLSVIPEYTINSTLDWF IDTONVPNCLAAGG PVPGCLDLGVWERNGVPVANFSORVYVDTATIOGFELGGRI PLFEGWSESGKYTLTASEITSGAKOGOPLGSOPRHSLNLGLNWR . ISISRTSDVNAAPGYONFVGFETGANGRR. IPVF SY . . Y YNVNRARWOGVETELKIPENDEWKLSINYTYNDGRDVSNG. ENRPLSDLPFHTANGTLDWK $\mathbf{G}$ $\mathbf{G} \mathbf{B}$ $\mathbf{P}$ T I $P$ N $L$ W

FepA

FePA EPGRTWYMSVNTHF 746

PfeA EPGRTFYTSITASF 746

Bf@A EPGRAYYATATVSF 735

BfrA LEGRRLWVSANITE 754

IIgA EDGRRYWLGLDIAF 652

CiI EDGRRYFMAVDYRE 663

GR
III

作

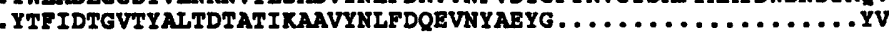
$\mathbf{Y}$ $V$ NL D

Fig. 3. Alignment of BfrA with enterobactin receptors (FepA, PfeA and BfeA of E. coli, P. aeruginosa and $B$. pertussis, respectively), IrgA ( $V$. cholerae outer-membrane virulence protein of unknown function) and Cir (colicin I, ferric-DHB and ferric-DHBS receptor). The comparisons were done with the PILEUP program of the Genetics Computer Group version 8 software. The region corresponding to the TonB box of $E$. coli receptors (residues 34-40 of FepA, region I) and two other regions (II and III) conserved with TonB-dependent receptors are indicated (overlined). Putative ligand binding sites of FepA are in bold type (residues 323-358 and 404-422; Murphy et al., 1990).

to the consensus Fur binding site (Calderwood \& Mekalanos, 1987) (positions $411-429$ in Fig. 2). This sequence was the only 'iron box' found with a homology search of the entire $3169 \mathrm{bp}$ of the sequence shown in Fig. 2. Another sequence with some similarity to the consensus Fur binding site overlaps the -35 hexamer ( 9 of 18 identical positions, bases $379-397$ in Fig. 2). 
Table 2. bfrA-phoA expression experiments

Cells were grown to late exponential phase in $\mathrm{SC}$ broth containing $50 \mu \mathrm{M} \mathrm{FeCl}_{3}(+\mathrm{Fe}$ ) or in $\mathrm{SC}$ broth containing $100 \mu \mathrm{M} \mathrm{DP}(-\mathrm{Fe})$.

\begin{tabular}{|c|c|c|}
\hline \multirow[t]{2}{*}{ B. bronchiseptica strain and relevant features } & \multicolumn{2}{|c|}{$\begin{array}{l}\text { AP units (mean } \pm S D, \\
n=3 \text { ) }\end{array}$} \\
\hline & $+\mathrm{Fe}$ & $-\mathrm{Fe}$ \\
\hline 191394 (bfrA:: TnphoA at base 1394 of $b f r A)$ & $7 \pm 3$ & $47 \pm 9$ \\
\hline $19233(b f r A:: \operatorname{Tn} p h o A$ at base 233 of $b f r A)$ & $9 \pm 3$ & $60 \pm 12$ \\
\hline $\begin{array}{l}\text { B013W (wild-type, } b f r A:: \operatorname{Tn} p h o A \text { at base } 233 \text { of } b f r A \text { in } \\
\text { integrated plasmid) }\end{array}$ & $8 \pm 4$ & $70 \pm 8$ \\
\hline B013F (as B013W, except fur mutant) & $81 \pm 7$ & $74 \pm 13$ \\
\hline
\end{tabular}

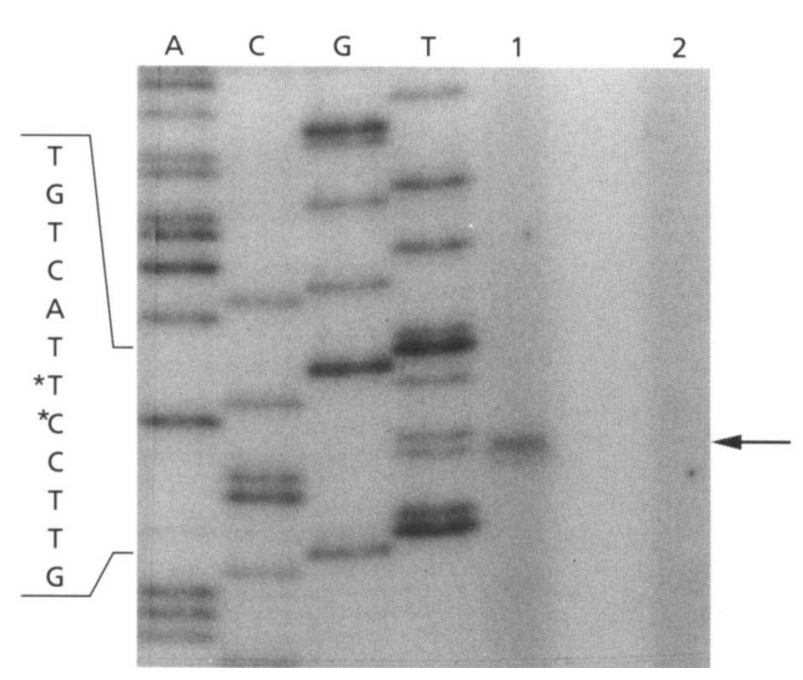

Fig. 4. Mapping the transcription start of the bfrA gene (arrow). A 5'-labelled oligonucleotide complementary to the $5^{\prime}$ sequence of the non-transcribed strand of the bfrA structural gene was used to prime CDNA synthesis from total RNA prepared from late-exponential phase cultures of strain 19385 (lanes 1 and 2) during iron-limiting (lane 1) and iron-replete (lane 2) conditions. The DNA sequence ( $A, C, G, T$ ) was generated on the non-transcribed strand with the same labelled oligonucleotide used for the primer extensions.

\section{Identification of a BfrA-PhoA fusion protein}

Western analysis of whole-cell, total-membraneenriched and outer-membrane-enriched protein extracts of iron-starved strain 191394 with antibody against the E. coli PhoA protein revealed a protein with an electrophoretic mobility corresponding to a protein of $97 \mathrm{kDa}$ (Fig. 5, lanes 1, 5 and 7). This is close to the predicted size of the BfrA-PhoA fusion protein which should contain the first 421 residues of the mature BfrA protein fused to 461 residues of PhoA. Smaller potential degradation products that reacted with anti-PhoA (Fig. 5, lanes 1,5 and 7) were also seen upon Western analysis of strain 191394 protein extracts.

We could not identify proteins corresponding to BfrA or $\mathrm{BfrA}-\mathrm{PhoA}$ fusion proteins in stained $7 \cdot 5 \%-12 \%$ gels after SDS-PAGE of protein extracts (using comparisons of strains 19385, 19233 and 191394) subjected to SDSPAGE on $7.5 \%$ and $10 \%$ gels. This was most likely due to the low abundance of these proteins (data not shown).

\section{The bfrA gene is not present in B. pertussis and $B$. parapertussis}

A 498 bp structural $b f r A$ gene fragment hybridized to identically sized restriction fragments from PstI and SalI digests of 19385 and B013N, B. bronchiseptica strains originally isolated from a dog and a pig, respectively (Fig. 6b, lanes 1 and 2; only the PstI digests are shown). Subsequently the $5^{\prime}$ bfrA region of strain $\mathrm{B} 013 \mathrm{~N}$ was amplified by PCR and sequenced. It was found that the sequence of the first 50 codons of $b f r A$ and the upstream region between etf $A$ and $b f r A$ was identical between strains 19385 and $\mathrm{B} 013 \mathrm{~N}$ (data not shown).

Unexpectedly, the $498 \mathrm{bp}$ internal $b f r A$ gene fragment did not hybridize to digests of three different $B$. pertussis isolates and two $B$. parapertussis clinical isolates (Fig. $6 a$, lanes $1,2,4,5,7$ and 8 ; only one isolate of each is shown). This 498 bp DNA fragment (the Sall fragment encompassing bases $\mathbf{8 7 5 - 1 3 7 3 ~ i n ~ F i g . ~ 2 ) ~ i s ~ h o m o l o g o u s ~}$ to the bfeA enterobactin receptor gene (about $60 \%$ identical) and under conditions of low hybridization stringency, identically sized $b f e A$ structural gene fragments from all three species could be seen to hybridize with the $b f r A$ gene probe (data not shown, Beall \& Sanden, 1995b). Additional evidence suggesting that $b f r A$ is not present in $B$. pertussis and $B$. parapertussis came from the inability to amplify different regions of the $b f r A$ gene from chromosomal DNA of these two species using $b f r A$-specific oligonucleotides (data not shown).

\section{bfrA mutants are not defective in utilization of alcaligin and enterobactin}

$b f r A$ mutants were first assessed for their ability to use the Bordetella siderophore alcaligin (Moore et al., 1995; Brickman \& Armstrong, 1996a). As shown in Table 3, $b f r A$ (and $b f e A$ ) mutants utilized alcaligin as efficiently 


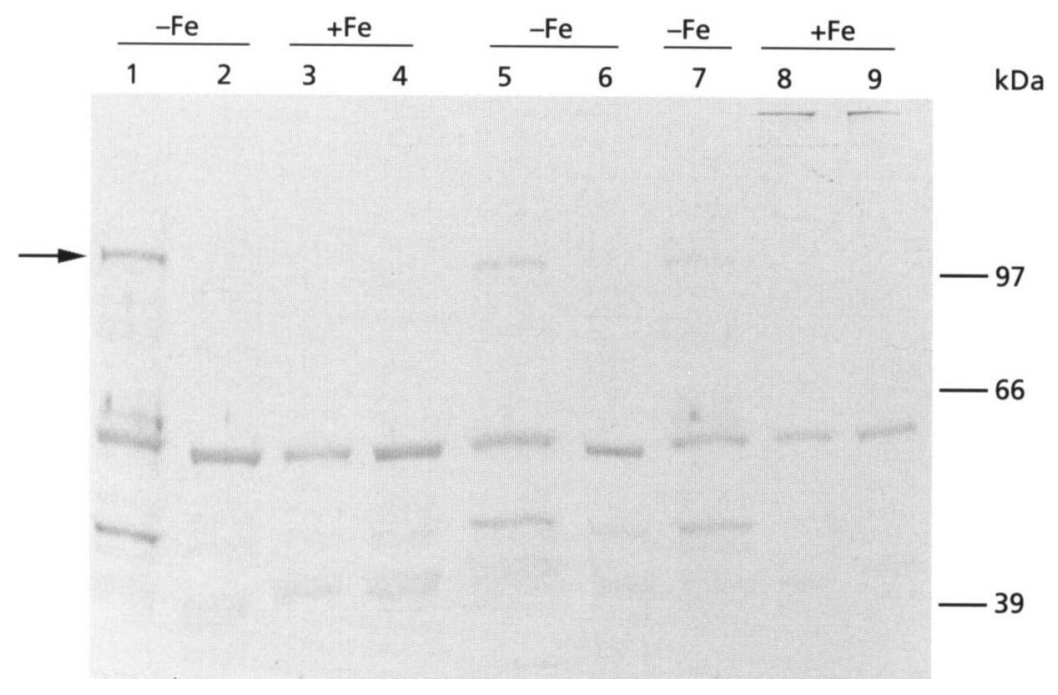

(a)

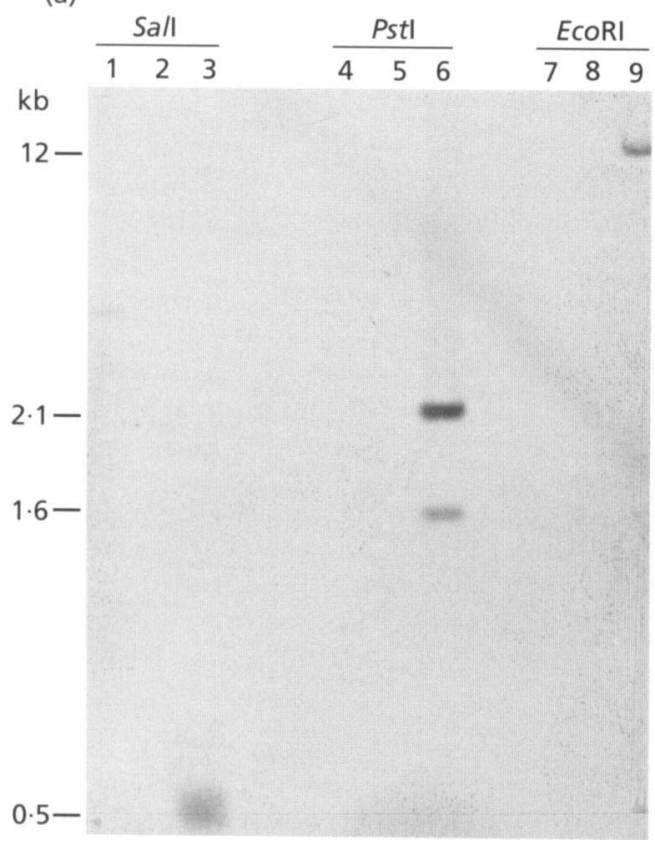

(b)

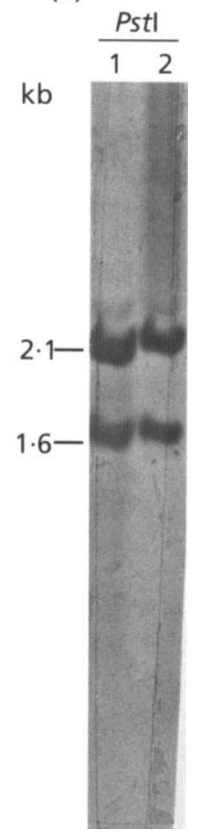

Fig. 5. Identification of a BfrA-PhoA fusion protein (arrow). Whole-cell extracts (lanes 1-4), total-membrane-enriched extracts (lanes 5-6) and outer-membrane-enriched extracts (lanes 7-9) from strain 191394 (bfrA::TnphoA) (lanes 1, 3, 5, 7 and 8) and wild-type strain 19385 (lanes 2, 4, 6 and 9). Proteins electrophoresed on SDSpolyacrylamide gels were transferred and immunostained with antiserum against the E. coli PhoA (AP) protein.
Fig. 6. (a) Lack of conservation of the bfrA gene among Bordetella species. Chromosomal DNA digests from $B$. pertussis (lanes 1, 4 and 7), B. parapertussis (lanes 2, 5 and 8) and B. bronchiseptica (lanes 3, 6 and 9) were subjected to high stringency Southern analysis. A 498 bp bfrA gene fragment (the Sall fragment encompassing bases 875-1373 in Fig. 2) was used as probe. (b) Conservation of the bfrA gene and flanking region between a pig and a dog isolate of $B$. bronchiseptica. Chromosomal DNA from dog isolate strain 19385 (lane 1) and pig isolate strain B013N (lane 2) was subjected to high stringency Southern analysis as shown in (a). as the wild-type parental strain. Consistent with previous results (Beall \& Sanden, 1995b), enterobactin utilization was abolished in $b f e A$ and $b f e A-b f r A$ double mutants, but was unaffected in $b f r A$ single mutants. Enterobactin appeared to be utilized more efficiently by $B$. bronchiseptica strains than by $B$. pertussis strains, which was also consistent with previous findings (Table 3, Beall \& Sanden, 1995b).

\section{Other iron sources utilized by B. bronchiseptica and B. pertussis}

During the course of attempting to find the specificity of the putative siderophore receptor $\mathrm{BfrA}$, it was sub- sequently found that B. bronchiseptica and B. pertussis could utilize the enterobactin degradation product DHBS, ferrichrome, desferrioxamine $B$ and haemin (Table 3). B. bronchiseptica bfrA mutants were unaffected in the use of these iron sources; however, DHBS-enhanced growth on SC-EDDHA was bfeAdependent in $B$. bronchiseptica and $B$. pertussis. The pattern of iron source usage by $B$. bronchiseptica bfeA$b f r A$ double mutants was identical to the pattern seen in $B$. bronchiseptica bfe $A$ mutants (Table 3 ).

DHB (an enterobactin precursor), salicylic acid (2hydroxybenzoic acid), rhodotorulic acid and citrate did not promote growth of $B$. pertussis and $B$. bronchiseptica (data not shown). 
Table 3. Siderophore and haemin utilization by wild-type, bfe $A$ mutant, bfrA mutant and bfeA-bfrA double mutant Bordetella strains on SC-EDDHA agar

The diameters of growth zones around disks containing the indicated iron source were measured in $\mathrm{mm}$ after $16 \mathrm{~h}$ (B. bronchiseptica) or $48 \mathrm{~h}$ (B. pertussis) at $35^{\circ} \mathrm{C}$. The results are the means for five separate experiments; the SD in each case was less than $3 \mathrm{~mm}$. ENT, enterobactin; ALC, strain B013NMn ${ }^{\mathrm{R}} 4$ supernatant which contains alcaligin; FC, ferrichrome; HEM, haemin; DF, desferrioxamine $\mathrm{B}$.

\begin{tabular}{|lrrrrrr|}
\hline Strain and features & ENT & DHBS & ALC & FC & HEM & DF \\
\hline B. bronchiseptica & & & & & & \\
19385 (wild-type) & 14 & 7 & 8 & 22 & 9 & 16 \\
$191394($ bfr $A:: \operatorname{Tn} p h o A)$ & 14 & 9 & 7 & 20 & 9 & 17 \\
$19233($ bfr $A:: \operatorname{Tn} p h o A)$ & 13 & 8 & 8 & 20 & 10 & 16 \\
$19387(b f e A)$ & 0 & 0 & 8 & 22 & 9 & 16 \\
$19233 \mathrm{~B}(b f r A:: \operatorname{Tn} p h o A b f e A)$ & 0 & 0 & 7 & 20 & 9 & 15 \\
B. pertussis & & & & & & \\
82 & 9 & 4 & 6 & 24 & 11 & 18 \\
$84($ bfeA) & 0 & 0 & 6 & 25 & 11 & 18 \\
\hline
\end{tabular}

\section{DISCUSSION}

In this study we describe the cloning, nucleotide sequence and iron-regulated expression of a gene, $b f r A$, that is homologous to siderophore receptors, especially to the ferric-DHB and ferric-DHBS receptor gene cir and ferric enterobactin receptor genes $(f e p A, p f e A$ and $b f e A)$. Since $b f r A$ mutants appeared fully functional in using the Bordetella siderophore alcaligin and appeared to have no readily apparent defect in iron uptake, BfrA may serve as a receptor for an exogenous siderophore synthesized by another organism.

$b f r A$ mutants appeared fully functional in the use of enterobactin, the enterobactin degradation product DHBS, ferrichrome, desferrioxamine $\mathrm{B}$ and haemin. To our knowledge, utilization of the latter four iron sources has not been documented previously in Bordetella. bfeAdependent utilization of DHBS was not unexpected, since the $E$. coli FepA receptor has been implicated in DHBS uptake (Hantke, 1990). It is likely that receptors other than BfeA, BfrA, and the as yet uncharacterized alcaligin receptor, function in the uptake of ferrichrome and desferrioxamine B. Studies of haemin uptake in Bordetella, which appeared to be an efficient process (Table 3), should prove interesting (the relatively small growth zone diameters measured around haemin disks do not reflect the observation that growth within these zones was more luxuriant than within the larger growth zones conferred by other iron sources (Table 3 ). Several pathogenic bacteria are capable of utilizing haemin as an iron source. For example, haemin uptake in Yersinia enterocolitica is TonB-dependent and requires an ironregulated specific outer-membrane receptor (Stojiljkovic \& Hantke, 1992). Haemin uptake in Streptococcus pneumoniae may be required for full virulence (Tai et al., 1993).

The levels of growth enhancement conferred by alcaligin, ferrichrome, desferrioxamine $\mathrm{B}$ and haemin appeared similar between $B$. bronchiseptica and $B$. pertussis, even though $B$. pertussis strains required a longer incubation period for these bioassays (Table 3 ). However, in spite of the ability of the B. pertussis bfe A gene expressed from a multicopy plasmid to complement B. bronchiseptica bfeA mutants (Beall \& Sanden, 1995b), there was a significant difference between the two subspecies in enterobactin-enhanced growth on SCEDDHA agar (Table 3 ). It is possible that this difference is due to the higher level of $b f e A$ expression that is evident in B. bronchiseptica (Beall \& Sanden, 1995b).

Two regions of FepA have been implicated in ligand binding by the use of monoclonal antibodies to block binding of ferric enterobactin and colicins to FepA (Murphy et al., 1990; Fig. 3). These experiments are consistent with the observation that these regions are fairly well conserved between FepA and two other enterobactin receptors, PfeA and BfeA (Fig. 3). The two putative ligand binding sites within FepA are largely not conserved in $\mathrm{Cir}, \operatorname{IrgA}$ or $\mathrm{BfrA}$, although significant homology is seen between all of these proteins throughout much of their respective lengths (Fig. 3). The apparent absence of the $b f r A$ gene in $B$. pertussis and $B$. parapertussis (Fig. 6) was unexpected, since these two species, together with $B$. bronchiseptica, are considered subspecies (Kloos et al., 1981). This result was different from that seen with the B. pertussis bfeA gene, which on the basis of hybridization experiments, was highly conserved between the three subspecies (Beall \& Sanden, 1995b).

Although the E. coli Cir receptor appears to function in ferric-DHB uptake (Hantke, 1990), the BfrA and IrgA putative siderophore receptors do not function detectably in ferric-DHB uptake since neither $V$. cholerae nor Bordetella species is capable of using this compound as an iron source (Goldberg et al., 1992; Table 3). The utilization of DHBS has not been reported 
in $V$. cholerae. DHBS functioned as a siderophore by a bfeA-dependent mechanism in $B$. bronchiseptica and also, less efficiently, in $B$. pertussis. We were unable to detect differences between wild-type and $b f r A$ mutant $B$. bronchiseptica strains using DHBS in iron uptake bioassays (Table 3). Ferric-DHBS and ferric-DHB uptake in $E$. coli are apparently mediated by the receptors Fiu, Cir and FepA (Hantke, 1990). It should be noted that we were unable to detect DHB or DHBS utilization in a triple fepA cir fiuA E. coli mutant carrying $b f r A$ on a multicopy plasmid (data not shown), but that is possibly a consequence of inefficient translation of $b f r A$ in E. coli due to a poor ribosome binding site (Fig. 2).

In $E$. coli, ferric siderophore receptor-mediated iron uptake across the outer membrane requires the cytoplasmic membrane TonB protein in an energy-dependent process (for review see Braun, 1995). Although a TonB protein has not been identified in Bordetella species, BfrA and BfeA are the two known OMPs from this genus that are homologous to the large family of TonB-dependent outer-membrane receptors. A region sharing high similarity to the seven residue 'Ton B box' is evident in BfrA, and differs from the Ton B box of FepA by only one conservative substitution (region I in Fig. 3). Two other regions in BfrA corresponding to TonB-dependent receptors (regions II and III of FepA in Fig. 3) are very similar to FepA and identical between all six of the OMPs at residues highly conserved in TonBdependent receptors (Braun, 1995) (Fig. 3).

The fur-dependent iron regulation of $b f r A$ (Fig. 4) and the putative Fur-binding sites preceding $b f e A$ (Fig. 2) indicate that its expression is controlled by the transcriptional regulator Fur complexed to iron. It is possible that the expression of $b f r A$ is affected by other transcription factors. The sequence AATAAATCCC, present at positions 338-347 upstream of the $b f r A$ promoter, is very similar to the consensus (G/C)CTAAATCCC implicated as a site required for transcriptional activation in iron-regulated promoters of Pseudomonas species (Rombel et al., 1995) (the 2 nonmatching bases at positions 338 and 339 were each seen in individual promoters used to generate the consensus). The significance of this sequence, if any, remains to be determined.

Recent work has shown that alcaligin production in $B$. bronchiseptica in certain strains is repressed not only by iron, but is also repressed by a bvg-dependent mechanism (Giardina et al., 1995). We have not detected differences in alcaligin production or $b f e A$ and $b f r A$ expression by varying virulence factor modulating signals such as temperature and $\mathrm{MgSO}_{4}$ concentrations in the two B. bronchiseptica backgrounds used for this study (data not shown).

Although IrgA, which shares extensive homology to BfrA, does not function in utilization of the $V$. cholerae siderophore vibriobactin and its function as an outermembrane receptor is unknown (Goldberg et al., 1992), $\operatorname{IrgA}$ is an iron-regulated virulence factor in an animal model (Goldberg et al., 1990). Future studies may determine if BfrA has a role in B. bronchiseptica virulence. As with $\operatorname{Irg} A$, the function of $B f r A$ as an outermembrane siderophore receptor also remains to be elucidated.

\section{ACKNOWLEDGEMENTS}

We are grateful to Tim Brickman, Klaus Hantke, Scott Stibitz and Ronald Taylor for strains, plasmids and advice. We thank Shambavi Subbarao for critically reading this manuscript. We appreciate the laboratory support provided by Gary Sanden.

\section{REFERENCES}

Beall, B. \& Sanden, G. N. (1995a). Cloning and initial characterization of the Bordetella pertussis fur gene. Curr Microbiol 30, 1-4.

Beall, B. \& Sanden, G. N. (1995b). A Bordetella pertussis fepA homologue required for utilization of exogenous ferric enterobactin. Microbiology 141, 3193-3205.

Bedzyk, L. A., Escudero, K. W., Gill, R. E., Griffin, K. J. \& Frerman, F. E. (1993). Cloning, sequencing and expression of the genes encoding subunits of Paracoccus denitrificans electron transfer flavoprotein. J Biol Chem 268, 20211-20217.

Bitter, W., Marugg, J. D., Weger, L. A., Tommassen, J. \& Weisbeek, P. J. (1991). The ferric-pseudobactin receptor PupA of Pseudomonas putida WCS358: homology to TonB-dependent Escherichia coli receptors and specificity of the protein. Mol Microbiol 5, 647-655.

Blake, M. S., Johnston, K. H., Russell-Jones, G. J. \& Gotschlich, E. C. (1984). A rapid, sensitive method for detection of alkaline phosphatase-conjugated anti-antibody on Western blots. Anal Biochem 136, 175-179.

Braun, V. (1995). Energy-coupled transport and signal transduction through the Gram-negative outer membrane via TonBExbB-ExbD-dependent receptor proteins. FEMS Microbiol Rev 16, 295-307.

Brickman, T. J. \& Armstrong, S. K. (1995). Bordetella pertussis fur gene restores iron repressibility of siderophore and protein expression to deregulated Bordetella bronchiseptica mutants. $J$ Bacteriol 177, 268-270.

Brickman, T. J. \& Armstrong, S. K. (1996a). Purification, spectroscopic analysis and biological activity of the macrocyclic dihydroxamate siderophore alcaligin produced by Bordetella bronchiseptica. Biometals 9, 191-203.

Brickman, T. J. \& Armstrong, S. K. (1996b). The ornithine decarboxylase gene odc is required for alcaligin siderophore biosynthesis in Bordetella spp.-putrescine is a precursor of alcaligin. $J$ Bacteriol 178, 54-60.

Brickman, E. \& Beckwith, J. (1975). Analysis of the regulation of Escherichia coli alkaline phosphatase using deletions and transducing phages. J Mol Biol 96, 307-316.

Calderwood, S. B. \& Mekalanos, J. J. (1987). Iron regulation of Shiga-like toxin expression in Escherichia coli is mediated by the fur locus. J Bacteriol 169, 4759-4764.

Dean, C. R. \& Poole, K. (1993). Cloning and characterization of the ferric enterobactin receptor (PfeaA) of Pseudomonas aeruginosa. $J$ Bacteriol 175, 317-324.

Finocchiaro, G., Ito, M., Ikeda, Y. \& Tanaka, K. (1988). Molecular cloning and nucleotide sequence of cDNAs encoding the alpha subunit of human electron transfer flavoprotein. J Biol Chem 263, 15773-15780.

Giardina, P. C., Foster, L. A., Musser, J. M., Akerly, B. J., Miller, J. F. \& Dyer, D. D. (1995). bvg repression of alcaligin synthesis in 
Bordetella bronchiseptica is associated with phylogenetic lineage. J Bacteriol 177, 6058-6063.

Giardina, P. C., Foster, L. A., Toth, S. I., Roe, B. A. \& Dyer, D. W. (1996). Identification of alcA, a Bordetella bronchiseptica gene necessary for alcaligin production. Gene 167, 133-136.

Goldberg, M. B., DiRita, V. J. \& Calderwood, S. B. (1990). Identification of an iron-regulated virulence determinant in Vibrio cholerae using TnphoA mutagenesis. Infect Immun 58, 55-60.

Goldberg, M. B., Boyco, S. A., Butterton, J. R., Stoebner, J. A., Payne, S. M. \& Calderwood, S. B. (1992). Characterization of a Vibrio cholerae virulence factor homologous to the family of TonB-dependent proteins. Mol Microbiol 6, 2407-2418.

Hantke, K. (1990). Dihydroxylbenzolyserine - a siderophore for E. coli. FEMS Microbiol Lett 67, 5-8.

Hawley, D. K. \& McClure, W. R. (1983). Compilation and analysis of Escherichia coli promoter DNA sequences. Nucleic Acids Res 11, 2237-2255.

von Heijne, G. (1985). Signal sequences: the limits of variation. $J$ Mol Biol 184, 99-105.

Kang, H. Y., Brickman, T. J., Beaumont, F. C. \& Armstrong, S. K. (1996). Identification and characterization of iron-regulated Bordetella pertussis alcaligin siderophore biosynthesis genes. $J$ Bacteriol 178, 4877-4884.

Kloos, W. E., Mohapatra, W. J., Dobrogosg, W. J., Ezzell, J. W. \& Manclark, C. R. (1981). Deoxyribonucleotide sequence relationships among Bordetella species. Int J Syst Bacteriol 31, 173-176. von Koenig, C. H. W., Tacken, A. \& Finger, H. (1988). Use of supplemented Stainer-Scholte broth for the isolation of Bordetella pertussis from clinical material. J Clin Microbiol 26, 2558-2560.

Lundrigan, M. D. \& Kadner, R. J. (1986). Nucleotide sequence of the gene for the ferrienterochelin receptor FepA in Escherichia coli: homology among outer membrane receptors that interact with TonB. J Biol Chem 261, 10797-10801.

Manoil, C. \& Beckwith, J. (1985). TnphoA: a transposon probe for protein export signals. Proc Natl Acad Sci USA 82, 8129-8133.

Merkel, T. J. \& Stibitz, S. (1995). Identification of a locus required for the regulation of bvg-repressed genes in Bordetella pertussis. $J$ Bacteriol 177, 2727-2736.

Moore, C. H., Foster, L.-A., Gerbig, D. G., Jr, Dyer, D. W. \& Gibson, B. W. (1995). Identification of alcaligin as the siderophore produced by Bordetella pertussis and Bordetella bronchiseptica. J Bacteriol 177, 1116-1118.

Moran, C. P. (1993). Measuring gene expression in Bacillus subtilis. In Molecular Biological Methods for Bacillus, pp. 267-293. Edited by C. R. Harwood \& S. M. Cutting. New York: Wiley.

Murphy, C. K., Kalve, K. I. \& Klebba, P. E. (1990). Surface topology of the Escherichia coli K12 enterobactin receptor. Mol Microbiol 6, 1309-1321.

Nau, C. D. \& Konisky, J. (1989). Evolutionary relationship between the TonB-dependent outer membrane transport proteins : nucleotide and amino acid sequences of the Escherichia coli colicin I receptor gene. J Bacteriol 171, 1041-1047.

Nikaido, H. (1994). Isolation of outer membranes. Methods Enzymol 235, 225-234.

Porra, R. J., Langman, L., Young, I. G. \& Gibson, F. (1972). The role of ferric enterochelin esterase in enterochelin-mediated iron transport and ferrochelatase activity in Escherichia coli. Arch Biochem Biophys 153, 74-78.

Rombel, I. T., McMorran, B. J. \& Lamont, I. L. (1995). Identification of a DNA sequence motif required for expression of ironregulated genes in pseudomonads. Mol Gen Genet 246, 519-528.

Simon, R., Priefer, U. \& Puhler, A. (1983). A broad host range mobilization system for in vivo genetic engineering: transposon mutagenesis in Gram-negative bacteria. Bio/Technology 1, 784-791.

Stibitz, S. (1994). Use of conditionally counterselective suicide vectors for allelic exchange. Methods Enzymol 235, 458-465.

Stojiljkovic, I. \& Hantke, K. (1992). Hemin uptake system of Yersinia enterocolitica: similarities with other TonB-dependent systems in Gram-negative bacteria. EMBO J 11, 4359-4367.

Tai, S. T., Lee, C. \& Winter, R. E. (1993). Hemin utilization is related to virulence in Streptococcus pneumoniae. Infect Immun 62, 5401-5405.

Taylor, R. K., Manoil, C. \& Mekalanos, J. J. (1989). Broad-hostrange vectors for delivery of $\operatorname{Tn} p h o A$ : use in genetic analysis of secreted virulence determinants of Vibrio cholerae. J Bacteriol 171, 1870-1878.

Received 17 June 1996; revised 3 September 1996; accepted 9 September 1996. 